Research Article

\title{
Early prediction of hypocalcaemia following total thyroidectomy by serial parathyroid hormone and ionized calcium assay
}

\author{
Sunil Kumar, Sakthivel Chinnakkulam Kandhasamy*, Anubhav Sangwan, Gopalakrishnan \\ Gunasekaran, Ranjithkumar Ramasamy, Sunil Kumar Meena
}

Department of General Surgery, Vardhman Mahavir Medical College and Safdarjung Hospital, New Delhi, India

Received: 16 June 2016

Accepted: 15 July 2016

*Correspondence:

Dr. Sakthivel Chinnakkulam Kandhasamy,

E-mail: medicosurgeon@gmail.com

Copyright: (C) the author(s), publisher and licensee Medip Academy. This is an open-access article distributed under the terms of the Creative Commons Attribution Non-Commercial License, which permits unrestricted non-commercial use, distribution, and reproduction in any medium, provided the original work is properly cited.

\begin{abstract}
Background: Total thyroidectomy is an accepted treatment modality for benign and malignant thyroid disease. Postoperative transient hypoparathyroidism leading to hypocalcaemia is one of the most frequent morbidities following total thyroidectomy.

Methods: 30 patients were included in this study, underwent total thyroidectomy and completion thyroidectomy. All measures for the preservation of parathyroid glands were taken. Intra-operative venous sample was taken after careful dissection of the parathyroid glands and post operatively at 6 hours, 24 hours, and 48 hours. Samples were analyzed for PTH, ionized calcium, total calcium and albumin levels. Patients were followed up for a period of one year.

Results: Nine patients (30\%) developed clinical hypocalcaemia in this study. Out of thirty patients, PTH values were below normal in $14(46.67 \%)$ intra-operatively, $13(43.33 \%)$ at 6 hours, $16(53.33 \%)$ at 24 hours, $12(40.0 \%)$ at 48 hours postoperatively. PTH had a sensitivity of $100 \%$ in predicting hypocalcaemia in these entire time interval. Ionized calcium values were below normal in $10(33.33 \%)$ patients intra operatively, $12(40 \%)$ at 6 hours, $8(26.67 \%)$ at 24 hours and $10(30 \%)$ at 48 hours post-operatively. It had a sensitivity of $55.6 \%, 55.6 \%, 66.7 \%$ and $100 \%$ respectively in predicting hypocalcaemia at these time interval.

Conclusions: Serum PTH proved to be a safe, convenient and easily available biomarker which can be measured to predict post-total thyroidectomy hypocalcaemia before the onset of serious symptoms.
\end{abstract}

Keywords: PTH, Ionized calcium, Total thyroidectomy, Completion thyroidectomy, Hypocalcemia

\section{INTRODUCTION}

Total thyroidectomy is the primary surgical modality in the treatment of thyroid malignancies and also frequently used for treatment of benign thyroid disorders. ${ }^{1}$

The incidence of post-operative hypocalcaemia following total thyroidectomy ranges from $1.5 \%$ to $71 \%$ and the condition may go unnoticed if not investigated carefully. ${ }^{2-5}$ It is often asymptomatic in the initial period. The onsets of symptom do not occur until 24-48 hours after surgery and is usually not easy to predict which patient will require oral calcium and/ or vitamin-D supplements. $^{6}$
No reliable predictors of clinically relevant hypocalcaemia after total thyroid resection have been individualized. The aim of this study is to evaluate the role of serial parathyroid hormone and serum ionized calcium assay during intra-operative and post-operative period in early prediction of hypocalcaemia in patient undergoing total thyroidectomy.

\section{METHODS}

The present study was conducted in the department of general surgery, Vardhman Mahavir Medical College and Safdarjung Hospital, New Delhi, India during the period of November 2013 to April 2015. Thirty patients 
included in this study, out of which 27 patients underwent total thyroidectomy and 3 patients underwent completion thyroidectomy.

\section{Inclusion criteria}

- Patients of either sex

- Age above 15 years

- Patients with thyroid disorders undergoing total thyroidectomy

\section{Exclusion criteria}

- Patients with renal dysfunction

- Hypo or hyperparathyroidism

- Hypothyroidism or secondary hyperthyroidism

- Undifferentiated and medullary thyroid carcinoma

- Patients with pre-existing metabolic disorders involving the parathyroid or bone diseases

- Patients receiving prior calcium supplementation.

Data on patients' profile was collected which included age, sex, clinical history, examination: general, physical and systemic, serum parathyroid hormone, serum calcium (ionized and total), serum albumin estimation, TSH, T3, T4 estimation, routine laboratory investigations, radiological examination (X-ray soft tissue neck, USG Neck), indirect laryngoscopy, FNAC of swelling (when indicated).

All patients underwent either total or completion thyroidectomy depends upon the etiology. During surgery details noted were identification and delineation of both recurrent laryngeal nerves throughout its course, identification of parathyroid glands along the posterior aspect of thyroid, parathyroid gland status and its vessel. Bipolar cautery was used for better identification and preservation of blood supply of parathyroid glands.

All measures for the preservation of parathyroid glands were taken. Intra-operative venous sample was taken after careful dissection of the parathyroid glands and post operatively at 6 hours, 24 hours, and 48 hours. Samples were analyzed for PTH, ionized calcium, total calcium and albumin levels. Patients were followed up for a period of one year. Reference value taken as PTH 15-65 $\mathrm{pg} / \mathrm{ml}$, ionized calcium 4.0-4.8 mg /dl, total calcium 8.5$10.5 \mathrm{mg} / \mathrm{dl}$, and serum albumin 3.5-5.0 g/dl.

Patients were followed up postoperatively with symptoms and objective signs of hypocalcaemia in immediate postoperative period, postoperative 6 hours, 24 hours and 48 hours. The symptoms of hypocalcaemia including paraesthesia, numbness, tingling, nausea, and tetany were evaluated. Trousseau's Sign and Chvostek's sign were evaluated.

\section{Statistical analysis}

Statistical analysis was performed by the SPSS program for Windows, version 17.0. Continuous variables were presented as mean $\pm \mathrm{SD}$, and categorical variables were presented as absolute numbers and percentage. Data were checked for normality before statistical analysis. Normally distributed continuous variables were compared using the unpaired $\mathrm{t}$ test, whereas the MannWhitney U test was used for those variables that were not normally distributed. Categorical variables were analyzed using either the chi square test or Fisher's exact test. For all statistical tests, $\mathrm{P}$ value less than 0.05 was taken to indicate a significant difference.

\section{RESULTS}

The patients were comparable in terms of age, sex, histopathology, type of surgery and clinical hypocalcaemia.

\section{Age distribution and clinical hypocalcaemia}

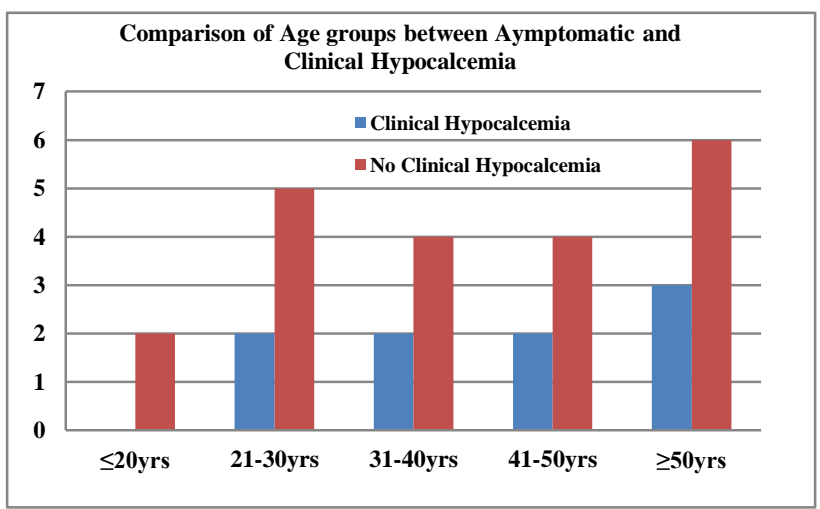

Figure 1: Age distribution of clinical hypocalcaemia.

The patient's age ranged from 16 years to 71 years. The mean age was 40.4 years (Figure 1 ).

\section{Sex distribution}

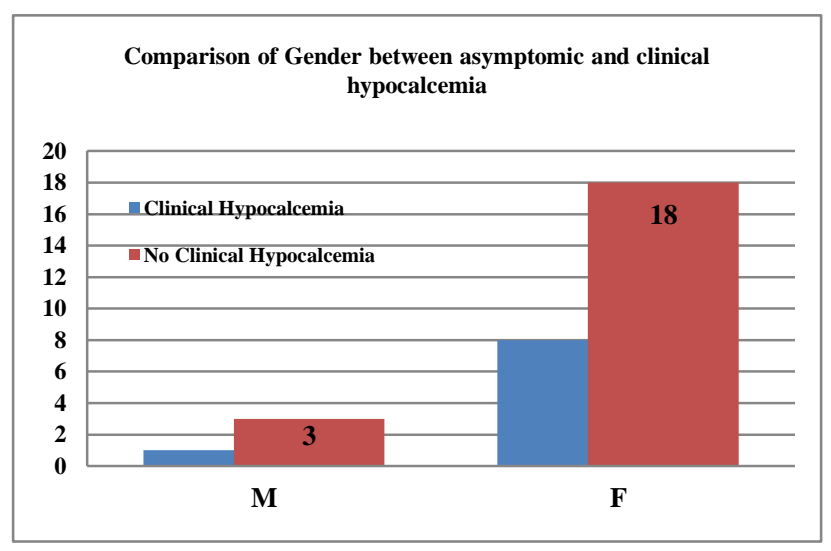

Figure 2: Sex distribution among clinical hypocalcaemia population.

In this study, 26 patients were female and 4 were male. Out of 9 patients who developed clinical hypocalcaemia, $8(88.9 \%)$ were female and $1(11 \%)$ was male. Out of 21 
patients who did not develop hypocalcaemia, $18(85.7 \%)$ were female and 3 (14.3) were male ( $\mathrm{P}$ value 1.00) (Figure 2).

\section{Type of surgery}

Out of 9 patients who developed clinical hypocalcaemia, $8(88.9 \%)$ underwent total thyroidectomy and $1(11.1 \%)$ underwent completion thyroidectomy. Out of 21 patients who did not develop clinical hypocalcaemia, 19 (90.5\%) underwent total thyroidectomy and $2(9.5 \%)$ underwent completion thyroidectomy $(\mathrm{P}=1.000)$. All patients who underwent completion thyroidectomy were previously operated for hemithyroidectomy for a benign lesion and histopathology turned out to be papillary carcinoma.

\section{Identification of parathyroid glands}

In all patients who underwent surgery, the parathyroid glands were identified and preserved.

\section{Histopathological distribution}

Out of 9 patients who developed clinical hypocalcemia, 4 $(44.4 \%)$ were operated for benign condition and 5
(55.6\%) were operated for malignant condition. Out of 21 patients who did not develop clinical hypocalcemia, 6 $(28.57 \%)$ were operated for benign condition and 15 $(71.43 \%)$ were operated for malignant condition.

\section{Clinical hypocalcaemia}

Clinical hypocalcaemia was defined in patients with symptoms and confirmed by clinical signs. Symptoms included were tingling, nausea, numbness, paraesthesia and tetany. Signs included were Trousseau's sign and Chvostek's sign.

Out of 30 patients, $9(30.0 \%)$ developed clinical hypocalcaemia and $21(70.0 \%)$ did not develop clinical hypocalcaemia.

\section{Trends in serum parathyroid hormone}

All patients had normal pre-operative serum PTH level. Out of 30 patients, 14 (46.67\%) had intra-operative PTH below normal. All patients with clinical hypocalcaemia had below normal PTH. Five (16.67\%) had decreased $\mathrm{PTH}$ in asymptomatic group $(\mathrm{PPV}=64.3 \%$, NPV $=$ 100\%) (Table 1).

Table 1: Distribution of clinical hypocalcaemia on the basis of serum PTH.

\begin{tabular}{|llllll|}
\hline \multirow{2}{*}{ Serum PTH } & Yes & \multicolumn{5}{c|}{ Clinical hypocalcaemia } \\
& Median & Min - Max & Mo & P Value \\
\hline Pre-operative & 51.4 & $16.80-64.0$ & 43.4 & $16.0-63.0$ & \\
\hline Intra-operative & 7.2 & $2.80-11.20$ & 20 & $2.70-34.00$ & 0.001 \\
\hline 6 hours & 5.5 & $1.60-8.80$ & 20.2 & $1.70-41.90$ & $<0.001$ \\
\hline 24 hours & 6.2 & $1.50-9.10$ & 22 & $2.20-44.10$ & $<0.001$ \\
\hline 48 hours & 7.4 & $1.90-12.6$ & 28.7 & $3.40-39.60$ & $<0.001$ \\
\hline
\end{tabular}

Table 2: Distribution of clinical hypocalcaemia on the basis of ionized calcium.

\begin{tabular}{|llll|}
\hline \multirow{2}{*}{ Serum ionized calcium } & \multicolumn{2}{c}{ Clinical hypocalcaemia } & P Value \\
& Yes & No & 0.804 \\
\cline { 2 - 4 } & Mean \pm SD & Mean \pm SD & 0.539 \\
\hline Pre-operative & $4.83 \pm 0.33$ & $4.79 \pm 0.035$ & 0.001 \\
\hline Intra-operative & $4.12 \pm 0.71$ & $4.27 \pm 0.54$ & $<0.001$ \\
\hline 6 hours & $3.59 \pm 0.60$ & $4.31 \pm 0.46$ & $<0.001$ \\
\hline 48 hours & $3.81 \pm 0.36$ & $4.33 \pm 0.24$ & $4.47 \pm 0.36$ \\
\hline
\end{tabular}

Thirteen (43.33\%) patients had 6 hours PTH below normal, out of which $9(30 \%)$ had clinical hypocalcaemia $(\mathrm{PPV}=69.2 \%, \mathrm{NPV}=100)$. Sixteen $(53.33 \%)$ patients had 24 hours PTH below normal, out of which $9(30 \%)$ had clinical hypocalcaemia $(\mathrm{PPV}=56.3 \%, \mathrm{NPV}=$ $100 \%)$. Twelve $(40 \%)$ patients had 48 hours PTH below normal, out of which 9 (30\%) had clinical hypocalcaemia $(\mathrm{PPV}=75.0 \%, \mathrm{NPV}=100 \%)($ Table 1$)$.

\section{Trends in levels of ionized calcium}

All patients had normal pre-operative ionized calcium. Ten $(33.33 \%)$ patients had 6 hours ionized calcium below 
normal, out of which $4(13.33 \%)$ were in symptomatic group (PPV $=38.5 \%$, NPV of $76.5 \%)$. At 6 hours period, $12(40 \%)$ patients had below normal ionized calcium, out of which $7(13.33 \%)$ were in symptomatic group (PPV = $35.7 \%$, NPV $=75.0 \%$ ) (Table 2 ).

Eight $(26.67 \%)$ patients had 24 hours ionized calcium below normal, out of which $7(23.33 \%)$ were in symptomatic group $(\mathrm{PPV}=85.7 \%, \mathrm{NPV}=87.0 \%)$. Ten $(33.33 \%)$ patients had 48 hours ionized calcium below normal, out of which $9(30 \%)$ were in symptomatic group $(\mathrm{PPV}=64.3 \%, \mathrm{NPV}=100)($ Table 2$)$.

\section{Trends in combined serum PTH and serum ionized calcium}

Combined monitoring of serum PTH and ionized calcium were statistically significant intra operatively, at 6 hours, 24 hours and 48 hours post-operatively (Table 3 ).

Table 3: PPV and NPV of combined serum PTH and serum ionized calcium levels.

\begin{tabular}{|llllll|}
\hline Combined & Sensitivity & Specificity & PPV & NPV & P value \\
\hline Pre-operative & $44.4 \%$ & $52.4 \%$ & $28.6 \%$ & $68.8 \%$ & 1.000 \\
\hline Intra-operative & $100.0 \%$ & $42.9 \%$ & $42.9 \%$ & $100.0 \%$ & 0.029 \\
\hline 6 hours & $100.0 \%$ & $57.1 \%$ & $50.0 \%$ & $100.0 \%$ & 0.004 \\
\hline 24 hours & $100.0 \%$ & $42.9 \%$ & $42.9 \%$ & $100.0 \%$ & 0.029 \\
\hline 48 hours & $100.0 \%$ & $61.9 \%$ & $52.9 \%$ & $100.0 \%$ & 0.003 \\
\hline
\end{tabular}

\section{Trends in total calcium level}

All patients had normal pre-operative total calcium. Mean total calcium in symptomatic patients was $10.11 \mathrm{mg} / \mathrm{dl}$ and in asymptomatic was $9.98 \mathrm{mg} / \mathrm{dl}$ ( $\mathrm{P}$ value 0.52 ). Eight $(26.67 \%)$ patients had decreased intra-operative total calcium, out of which $4(13.33 \%)$ were in symptomatic group. Mean total calcium in symptomatic patients was $8.59 \mathrm{mg} / \mathrm{dl}$ and in asymptomatic was 9.09 $\mathrm{mg} / \mathrm{dl}(\mathrm{P}=0.0381, \mathrm{PPV}=50.0 \%, \mathrm{NPV}$ of 77.3$)$.

Eight $(26.67 \%)$ patients had decreased 6 hours total calcium, out of which $5(16.67 \%)$ were in symptomatic group. Mean total calcium in symptomatic patients was $7.71 \mathrm{mg} / \mathrm{dl}$ and in asymptomatic was $9.34 \mathrm{mg} / \mathrm{dl}(\mathrm{PPV}=$ $62.5 \%, \mathrm{NPV}=81.8 \%, \mathrm{P}=0.008)$. Eight $(26.67 \%)$ patients had decreased 24 hours total calcium, out of which $6(20 \%)$ were in symptomatic group. Mean total calcium in symptomatic patients was $8.0 \mathrm{mg} / \mathrm{dl}$ and in asymptomatic was $9.33 \mathrm{mg} / \mathrm{dl}(\mathrm{PPV}=75.0 \%, \mathrm{NPV}=$ $86.4 \%, \mathrm{P}=<0.001)$. Nine $(30 \%)$ patients had decreased 48 hours total calcium and all of them had clinical hypocalcaemia. Mean total calcium in symptomatic patient was $7.76 \mathrm{mg} / \mathrm{dl}$ and in asymptomatic was 9.56 $\mathrm{mg} / \mathrm{dl}(\mathrm{PPV}=100 \%, \mathrm{NPV}=100 \%, \mathrm{P}<0.001)$.

\section{Trends in serum albumin level}

Changes in serum albumin alter the total calcium levels significantly because most protein bound calcium associates with albumin (80\%). In this study, all patients had normal serum albumin levels during the course of study.

\section{DISCUSSION}

In our study, the mean age of the patient $(n=30)$ was 40.4 years (range 16 years - 71 years) with maximum number $(\mathrm{n}=16)$ of patients in the age group $>50$ years $(30 \%)$ and 21 to 30 years $(23.3 \%)$. The present study showed highest incidence $(30 \%)$ in $>50$ years of age which is similar to the study conducted by Rosa KM et al. ${ }^{7}$ This might be due to difference in presentation of benign goitre, papillary and follicular carcinoma.

Male:female ratio in the present study was 1:6.5, which was similar to other studies where the male to female ratio was between $1: 3.3$ to $1: 5.25 .^{8-10}$ This might be due to increased incidence of thyroid disease in women.

In the present study, parathyroid glands were identified in all patients and preserved. The peculiar anatomy of the parathyroid glands was that, they lie close to the posterior aspect of thyroid gland and during surgery, glands may be inadvertently removed or artery gets damaged. So careful dissection was at most important in preserving the vascularity of the glands. These results were similar to study conducted by Abboud B et al. ${ }^{11}$

In the present study, maximum number of patients $(\mathrm{n}=$ $27,90 \%$ ) underwent total thyroidectomy. The result was comparable to the study conducted by Iqbal $\mathrm{M}$ et al. ${ }^{12}$

In our study, 20 patients $(66.67 \%)$ were operated for malignant conditions. Clinical hypocalcaemia developed in $55.6 \%$ of those operated for malignant thyroid disease, predominantly papillary carcinoma. These results were comparable to the study by Rosa KM et al. ${ }^{7}$ 
In this study, 9 patients $(30 \%)$ developed clinical hypocalcaemia. Review of several series of data revealed the incidence of transient hypocalcaemia to vary from $16.5 \%$ to more than $71 \%$. ${ }^{2,3}$ Transient hypocalcaemia is a frequent complication after total thyroidectomy, but in this study it was comparatively low and transient. This was comparable to previous study. ${ }^{7}$ Permanent hypoparathyroidism was a less frequent complication, with the incidence of 1.5 to $1.8 \% .^{4,5}$ Permanent hypocalcaemia was absent in this study during the follow up period of one year.

Recently published studies concern the usefulness of perioperative PTH assay (by both traditional and quick assay), in the identification of patients who are at the risk for the development of symptomatic hypocalcaemia and hypoparathyroidism after total thyroidectomy.

In the present study, serum PTH value of $15 \mathrm{pg} / \mathrm{ml}$ was taken as lower limit for prediction of symptomatic hypocalcaemia in postoperative period. Median value of serum PTH level declined (from $51.4 \mathrm{pg} / \mathrm{ml}$ to $7.2 \mathrm{pg} / \mathrm{ml}$ ) from pre-operative to intra-operative levels. The decline in levels was mainly in patients who developed hypocalcaemia symptoms subsequently and this had brought down the median value. Out of 30 patients, 14 had low PTH intra-operatively but only 9 developed symptomatic hypocalcaemia. Five patients had low intraoperative level of PTH, but postoperatively didn't develop symptomatic hypocalcaemia. None of the patients, who had normal PTH level intra-operatively, developed clinical hypocalcaemia. The intra-operative PTH had sensitivity of $100 \%$ and specificity of $76.2 \%$ in early prediction of symptomatic hypocalcaemia (P $<0.001)$.

Lombardi CP et al reported that a $75 \%$ decline of serum PTH during the operation correlates with the development of hypocalcaemia. ${ }^{13}$ However, the overall accuracy of this method was $75 \%$. Moreover, this technique requires the collection of several samples during the operation, and the use of quick PTH assay. A single intraoperative PTH measurement by conventional assay was proposed for the prediction of post-operative hypocalcemia. ${ }^{13}$ An intact PTH level below the normal range correlated highly with postoperative hypocalcaemia, after the end of operation (resection of the second lobe and skin closure, respectively), thus not allowing for an adequate PTH decay after thyroid removal and parathyroid glands injury.

In our study, 13 patients had low 6 hours serum postoperative PTH value, of which 9 patients developed clinical hypocalcaemia. None of the patients who had normal level of PTH at 6 hours developed symptomatic hypocalcaemia. The 6 hours post-operative PTH had sensitivity of $100 \%$ and specificity of $81.0 \%$ in early prediction of symptomatic hypocalcaemia $(\mathrm{P}$ value $=$ $0.001)$.
Out of 16 patients who had low 24 hours post-operative PTH value, 9 developed clinical hypocalcaemia. None of the patients who had normal level of PTH at 24 hours developed symptomatic hypocalcaemia. The 24 hours post-operative PTH had sensitivity of $100 \%$ and specificity of $66.7 \%$ in early prediction of symptomatic hypocalcaemia $(\mathrm{P}=0.001)$.

Out of 12 patients who had low 48 hours post-operative PTH value, 9 developed clinical hypocalcaemia. None of the patients who had normal PTH level at 48 hours developed symptomatic hypocalcaemia. The 48 hours post-operative PTH had sensitivity of $100 \%$ and specificity of $85.7 \%$ in early prediction of symptomatic hypocalcaemia $(\mathrm{P}=<0.001)$.

In this study, monitoring of PTH was significant at all duration. These results were comparable to study conducted by Kim JP et al. ${ }^{14}$ However in all of them PTH returned to normal within 7 th post-operative day. This study confirmed that a single intra-operative PTH measurement at the earliest can identify patients who are at risk of post-operative hypocalcaemia. Similar finding was also reported by Warren et al15 who reported intraoperative PTH level of greater than $15 \mathrm{pg} / \mathrm{ml}$ after total thyroidectomy carried a low risk of post-operative hypocalcaemia. Similar findings were also reported by and Lombardi et al and Lam. ${ }^{13,16}$ The cut off values of PTH level were different in their observations.

All patients of clinical hypocalcaemia group developed symptoms at 48-72 hours period and were treated with intravenous and oral calcium supplementation. In these patients, ionized calcium returned to normal in 5 to 7 days period. Serum ionized calcium after 48 hours would not be reliable but was measured in view of monitoring the response to treatment.

In the present study, out of 9 cases of symptomatic hypocalcaemia, ionized serum calcium below normal level was found in 4 patients during intra-operative period, in 7 patients at 6 hours post-operative period, in 7 patients at 24 hours post-operative period and in all 9 patients at 48hours post-operative period. Serum ionized calcium had a sensitivity of $55.6 \%$ intra-operatively, $55.6 \%$ at 6 hours, $66.7 \%$ at 24 hours, $100 \%$ at 48 hours post-operatively. Thus monitoring of ionized calcium was statistically significant at 6,24 and 48 hours. These results were comparable to study conducted by Viswanathan $\mathrm{KV}$ et al in which statistically significant association was found in the occurrence of clinical hypocalcaemia on post-operative days 1,2 and $3 .{ }^{17}$

In the present study, monitoring of ionized calcium along with PTH increased the sensitivity of symptomatic hypocalcaemia and it was significant at all duration. These results were comparable to study conducted by Rosa KM et al in which statistically significant correlation between PTH and ionized calcium values (P < $0.0001)^{7}$ 
The lowest total calcium levels were typically recognized 24 to 48 hours after total thyroidectomy, though hypocalcaemia may be delayed. ${ }^{18}$ However, even though the serum calcium slope may correlate with the development of clinical hypocalcaemia, these results often are not useful until 12 or 24 hours after surgery. ${ }^{19}$ This delay can postpone therapy and prolong hospitalization.

Out of 9 cases of symptomatic hypocalcaemia, serum total calcium below normal level was found in 4 patients during intra-operative period, in 5 patients at 6 hours, in 6 patients at 24 hours and in all patients at 48 hours postoperative period. Thus, serum total calcium levels has sensitivity of $44.4 \%$ intra-operatively, $55.6 \%$ at 6 hours, $66.7 \%$ at 24 hours, $100 \%$ at 48 hours post-operatively. The measurements of total calcium were significant at 6 , 24 and 48 hours. These results were comparable to the study conducted by Islam MS et al and Iqbal M et al. ${ }^{10,12}$ Out of 30 patients in this study, none of the patient had serum albumin values below than $3.5 \mathrm{mg} / \mathrm{dl}$.

\section{CONCLUSION}

Transient hypocalcaemia is not an infrequent complication after total thyroidectomy which prevents the surgeons from performing total thyroidectomy on day care basis.

Safe surgical technique to identify and preserve parathyroid glands along with its blood supply has bearing on the development of post-operative hypocalcaemia. Size of the goiter and histopathology has no correlation with the development of symptomatic hypocalcaemia, if proper surgical technique is practiced.

Serum PTH level $(<15 \mathrm{mg} / \mathrm{dl})$ proved to be a safe, convenient and easily available biomarker which can be measured to predict post-total thyroidectomy hypocalcaemia before the onset of serious symptoms. Significant post-operative decrease in PTH and ionized calcium may provide objective criteria for identifying patients predisposed to develop symptomatic hypocalcaemia.

Intra operative PTH, post-operative PTH (at 6 hours, 24 hours and 48 hours) and ionized calcium post-operatively at 24 hours and 48 hours were found to be the best objective parameter to predict symptomatic hypocalcaemia. Intra-operative and 6 hours postoperative serum ionized calcium alone is not a reliable predictor of symptomatic hypocalcaemia. Total calcium and serum albumin levels did not correlate with development of hypocalcaemia with good accuracy.

\section{ACKNOWLEDGEMENTS}

In achieving this personal milestone, authors would first of all thank the almighty for providing us with knowledge and the chance.
Authors would like to thankful to Dr. Sunil Kumar, head of department of general surgery, VMMC and Safdarjung hospital for his constant support and encouragement. Authors would also thankful to Dr. Jayashree Bhatacharjee, Principal of Vardhman Mahavir Medical College and Dr. B.D. Athani, medical superintendent VMMC and Safdarjung Hospital, New Delhi for their valuable support in conduction of this study. Authors would also like to thank the staff of department of general surgery and department of pathology for their support during the study.

\section{Funding: No funding sources \\ Conflict of interest: None declared}

Ethical approval: The study was approved by the institutional ethics committee

\section{REFERENCES}

1. Bhattacharyya N, Fried MP. Assessment of the morbidity and complications of total thyroidectomy. Arch Otolaryngol Head Neck Surg. 2002;128:38992.

2. Pattou F, Combemale F, Fabre S, Carnaille B, Decoulx M, Wemeau JL, et al. Hypocalcemia following thyroid surgery: incidence and prediction of outcome. World J Surg. 1998;22:718-24.

3. Lindblom P, Westerdahl J, Bergenfelz A. Low parathyroid hormone levels after thyroid surgery: a feasible predictor of hypocalcemia. Surgery. 2002;131(5):515-20.

4. Lewandowicz M, Kuzdak K, Pasieka Z. Intraoperative parathyroid hormone measurement in thyroidectomized patients: preliminary report. Endocr Regul. 2007;41(1):29-34.

5. Hermann M, Ott J, Promberger R, Kober F, Karik M, Freissmuth M. Kinetics of serum parathyroid hormone during and after thyroid surgery. Br J Surg. 2008;95(12):1480-7.

6. Nhan C, Dolev Y, Mijovic T, Rivera JA, KallaiSanfacon MA, Mlynarek AM, et al. Vitamin D deficiency and the risk of hypocalcemia following total thyroidectomy. Otolaryngol Head Neck Surg. 2012;41:401-6.

7. Rosa KM, de Matos LL, Cernea CR, Brandao LG, de Araujo Filho VJF. Postoperative calcium levels as a diagnostic measure for hypoparathyroidism after total thyroidectomy. Arch Endocrinol Metab. 2015;59(5):428-32.

8. Nair CG, Babu MJ, Menon R, Jacob P. Hypocalcaemia following total thyroidectomy: an analysis of 806 patients. Indian J Endocrinol Metab. 2013;17(2):298.

9. Liu Q, Djuricin G, Prinz RA. Total thyroidectomy for benign thyroid disease. Surgery. 1998;123(1):27.

10. Islam MS, Paul D, Sultana T, Rahman MQ, Rehana $\mathrm{Z}$, Ahmed ANN. Evaluation of serum calcium level measurement in total thyroidectomy patients - a 
prospective study in tertiary hospitals. Bangladesh $\mathbf{J}$ Med Biochem. 2011;4(1):4-9.

11. Abboud B, Sargi Z, Akkam M, sleilaty F. Risk factors for post thyroidectomy hypocalcemia. J Am Coll Surg. 2002;195:456-61.

12. Iqbal M, Subhan A, Baig MS, Shah MS. Frequency of hypocalcemia in total thyroidectomy. J Surg Pakistan. 2010;15(2):87-91.

13. Lombardi CP, Raffaelli M, Princi P. Early prediction of post-thyroidectomy hypocalcemia by a single iPTH measurement. Surgery. 2004;136:123640.

14. Kim JP, Park JJ, Son HY, Kim RB, Kim HY, Woo $\mathrm{SH}$. Effectiveness of an I-PTH measurement in predicting post thyroidectomy hypocalcemia: Prospective controlled study. Yonsei Med J. 2013;54(3):637-42.

15. Warren FM, Andersen PE, Wax MK, Cohen JI. Intraoperative parathyroid hormone levels in thyroid and parathyroid surgery. Laryngoscope. 2002;112:1866-70.

16. Lam A, Kerr PD. Parathyroid hormone: an early predictor of postthyroidectomy hypocalcaemia. Laryngoscope. 2003;113:2196-200.

17. Viswanathan KV, Jithunath MR, Viswanathan M. Incidence of post-operative hypocalcaemia after thyroidectomy: a case controlled study. Int J Adv Health Sci. 2014;1(5):1-9.

18. Markuszewska MP, Kobiela J, Stefaniak T, Andrzej J, Lachinski AJ, Sledzinski Z. Postoperative PTH measurement as a predictor of hypocalcemia after thyroidectomy. Polski, Przeglad Chirurgiczncy. 2010;82:24-8

19. Leahu A, Carroni V, Biliotti G. Calcium level, a predictive factor of hypocalcaemia following total thyroidectomy. J de Chirurgie. 2009;5:148-52.

Cite this article as: Kumar S, Kandhasamy SC, Sangwan A, Gunasekaran G, Ramasamy R, Meena SK. Early prediction of hypocalcaemia following total thyroidectomy by serial parathyroid hormone and ionized calcium assay. Int Surg J 2016;3:1611-7. 